\title{
Measuring specificities of dissipation factor of electrical equipment in substations
}

\author{
Gerards Gavrilovs (PhD student, Riga Technical University), Sandra Vītoliṇa (Docent, Riga Technical University)
}

\begin{abstract}
Measuring techniques of dielectric losses $\tan \delta$ of high voltage equipment are discussed and compared in this paper. There are several methods for determining $\tan \delta$ and capacitance values in high voltage substation on site.

Simple measuring methods like GST and UST can be put into practice without result corrections in ideal conditions. However electrical field in substation originates negative affect on measuring results, therefore different connection schemes of measuring methods have to be used.
\end{abstract}

Keywords - capacitance, dielectric losses, dissipation factor, measuring specificity.

\section{PHYSICAL BACKGROUND OF INSULATION DISSIPATION FACTOR}

The quality of the transformer's insulation and the efficacy of the moisture removal processing are evaluated through the results of Insulation Dissipation Factor Tests and Insulation Resistance Tests.

The insulation level of high voltage equipments, for example power transformers, is accordant to the required quality when equipment departs from factory. The environmental pollution and natural ageing in maintenance has an affect on maintained equipment. There are various factors which have an influence on insulation of equipment, such as:

- the absorption of moisture,

- internal arch and disruptive discharge,

- high temperature,

- overload,

- sludge and dust,

- chemical reaction,

- ageing.

Electric power is dissipated in all dielectric materials, usually in the form of heat. In a capacitor made of a dielectric placed between conductors, the typical lumped element model includes a lossless ideal capacitor in series with a resistor termed the equivalent series resistance (ESR) as shown in "Fig. 1" [1]. The ESR represents losses in the capacitor. Note that the ESR is not simply the resistance that would be measured across a capacitor by an ohmmeter. The ESR is a derived quantity with physical origins in both the dielectric's conduction electrons and dipole relaxation phenomena. In a dielectric only one of either the conduction electrons or the dipole relaxation typically dominates loss [2].

In real situation, insulation is series or parallel connected resistance losses and the equivalent scheme depended on losses disposition is shown in "Fig. 1" and accordant equations (1).

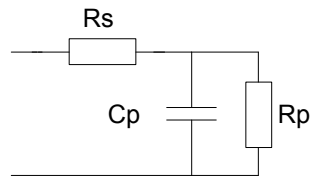

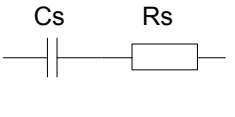

b)

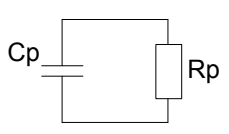

c)
Fig.1. Substitution schemes of connection

For the case of the conduction electrons being the dominant loss, then

$$
\begin{gathered}
\tan \delta_{p}=\frac{1}{R_{p} \omega C_{p}} ; \\
\tan \delta_{S}=R_{S} \omega C_{S} ; \\
R_{V}=E S R=\frac{\sigma}{\varepsilon C \omega^{2}},
\end{gathered}
$$

where:

$\sigma$ - is the dielectric's bulk conductivity,

$\omega$ - is the angular frequency of the AC current $i$,

$\varepsilon$ - is the lossless permittivity of the dielectric, and

$C$ - is the lossless capacitance.

If the capacitor is used in an AC circuit, the dissipation factor (DF) or dielectric losses (tan $\delta$ ) will vary depending on the dielectric material and the frequency of the electrical signals. Due to the non-ideal capacitor DF is expressed as the ratio of the resistive power loss in the ESR to the reactive power oscillating in the capacitor, or

$$
D F=\omega C \cdot E S R
$$

When representing the electrical circuit parameters as vectors in a complex plane, known as phasors, a capacitor's dissipation factor is equal to the tangent of the angle between the capacitor's impedance vector and the negative reactive axis [2]. This gives rise to the parameter known as the loss tangent $\delta$ where:

$$
\tan \delta=\frac{E S R}{X_{C}}=D F
$$

\section{TRADITIONAL MEASURING METHODS OF CAPACITANCE AND INSULATION DISSIPATION FACTOR}

\section{A. Capacitance test}

The easiest way of measuring capacitance in substation on site is to use two vector voltmeters (VV), "Fig. 2". 


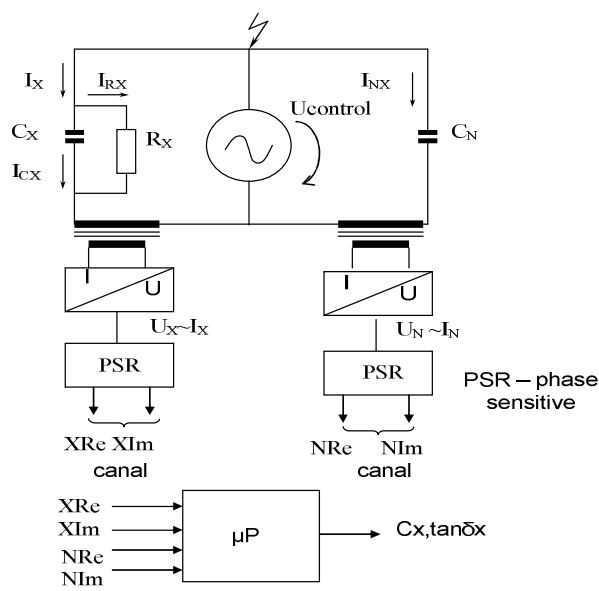

Fig. 2. Two vector voltmeters' measurement

The first voltmeter measures the voltage on bench-mark capacitor $\mathrm{C}_{\mathrm{N}}$, but the second voltmeter measures the voltage on examination object through its capacitance $\mathrm{C}_{\mathrm{X}}$. Those voltages are converted to real and imaginary component and thereafter object's capacitance $\left(\mathrm{C}_{\mathrm{X}}\right)$ and dielectric losses $\left(\tan \delta_{X}\right)$ are determined. This method is reasonable and applicable to detect $\mathrm{I}_{\mathrm{CX}}$ and $\mathrm{I}_{\mathrm{RX}}$ in its limits $0.1 \mathrm{I}_{\mathrm{CX}}<\mathrm{I}_{\mathrm{RX}}<2 \mathrm{I}_{\mathrm{CX}}$ when solid insulation of examination object is wet and dielectric losses is about $\tan \delta=10 \%$ (without substation's electrical field influence).

The preventive measurements normally are done in substation on site and it is the reason of substation's electrical field influence on determined values. This influence of electric field might be not so critical. It depends on technical condition of the object - if $\tan \delta$ value is insignificant there is no necessity to use guard method (see Tab.1. case A). Sometimes this influence of electrical field can be very negative during decision making on object's technical condition. It has been noticed in practice, that due to negative influence on measuring results distortion can reach two times. It is very important when measured values are on critical limits (see Tab.1. case B). For that reason it is accepted to use influence compensation of electrical field, principle of which is shown in "Fig. 3".

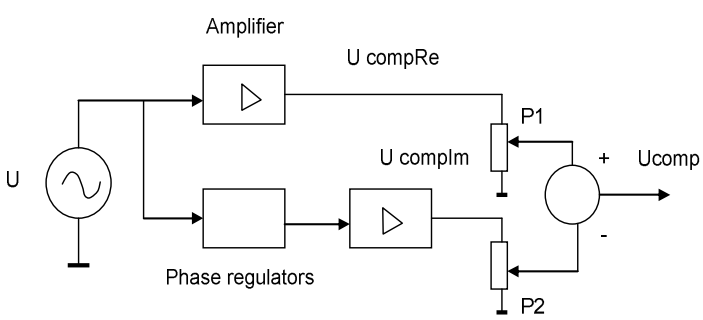

Fig. 3. Substation's electrical field compensation principle

The module is used to repress the electrical field's influence on the input signal. There is: network control voltage $\left(\mathrm{U}_{\text {control }}\right)$, amplifier grade, which can be in "+" or "." position and $90^{\circ}$ phase regulator. Both signals $U_{\text {compe }}$ and $\mathrm{U}_{\text {compIm }}$ are compared by potentiometers $\mathrm{P} 1$ and $\mathrm{P} 2$ and introduced in next grade. Thereby module shown in "Fig. 3"
Electrical Machines and Apparatus / Elektriskās Mašīnas un Aparāti

can generate signals with values from 0 to $\mathrm{U}_{\text {control }}$ and phase displacement from $0^{\circ}$ to $360^{\circ}$. The influence of substation's electrical field on examination object might be reduced to minimum.

\section{B. Dissipation factor $(\tan \delta)$}

Dissipation factor of tested object describes:

- chemical deterioration due weather, temperature and overheating effect,

- moisture content, effect of oil, sludge and etc.,

- various types of leakage, ionization.

Many faults can be detected by preventive and specific insulation tests. To determine capacitance and dielectric losses of the object, it is necessary to know the construction and insulation type of the object under test, for example oil type and quality. Assessment of test results must be done only by comparing current values with previous measuring results or even better with initial results before maintenance. The test results can be compared with analogical object, if the data output is not satisfactory.

If tan $\delta$ is changing considerably after the voltage is applied and reduced to a certain magnitude there is a possibility of ionization process in insulation, which can lead to the breakdown of the insulation. Partial capacitance's increase also indicates ionization process, which occurs in empty spaces of insulation. The increase of $\tan \delta$ and capacitance indicates insulation's wetting, but if only $\tan \delta$ increases that points at a thermal fault.

The measurement of insulation capacitance and dissipation factor is carried out using a capacitance bridge. The values of capacitance and their corresponding values of insulation dissipation factor are measured. Each object has different its unique measuring range (Tab.1.) and rate-fixer values.

„Fig. 4" shows the measurement of capacitance and dissipation factor of the $\mathrm{HV}$ to $\mathrm{LV}$ capacitance, using guarded measurements [3]. "Fig. 5" is for the low to ground capacitance.

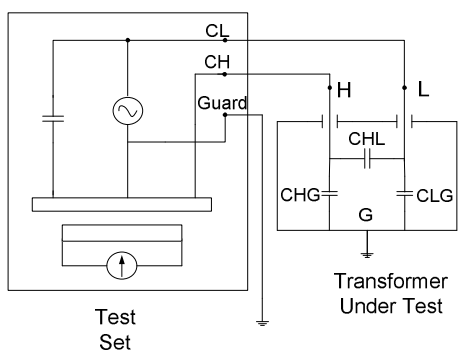

Fig. 4. Measurement of dissipation factor and capacitance - HV to LV

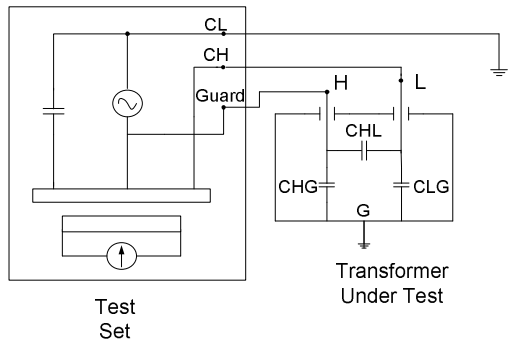

Fig. 5. Measurement of dissipation factor and capacitance - LV to ground 


\section{PARAMETERS AFFECTING MEASURING RESULTS}

\section{A. Temperature effect}

The main cause of increased $\tan \delta$ is increasing temperature. Tan $\delta$ increasing leads to the increase of heat desorbing and temperature rise. This process can result in insulation breakdown.

At constant temperature $\tan \delta$ can vary, it depends on insulation's technical condition. The measurements should be done at temperature $+5{ }^{\circ} \mathrm{C}$ and above [7]. It is very important to determine real temperature on measuring time, to choose a coefficient of dielectric losses. Base temperature is $20{ }^{\circ} \mathrm{C}$. The object surface's temperature must be higher than environment temperature to avoid condensation on it.

\section{B. Moisture effect}

In case when air humidity is at $50 \%$ and surface is polluted by industrial dirt, the measuring mistakes can be very serious. The effect of surface's humidity on measuring results is minimized in dry, sunny day, when air humidity is $80 \%$ and less. Surface's pollution even of power transformers bushings with higher rated voltage level than test voltage, creates serious measuring mistake.

Dry and clean insulation must be provided to ensure accurate measurements. The influence of surface's leakage can be eliminate with UST (Ungrounded Specimen Test) method [4] for power transformers' bushings since it has measuring tap (output).

\section{INFLUENCE OF SUBSTATION'S ELECTRICAL FIELD}

The substation's electrical field has an influence on equipment measuring results. The electrical field influence can be minimized by special measuring equipment and additional use of two polarities method with phase regulator (Tab.1.). The influence of electrical field depends on: field strength, equipment's capacitance, and dielectric losses. Adverse weather conditions amplify field influence. It is possible to gain also negative $\tan \delta$. It can be minimized by:

- using higher test voltage;

- $\quad$ switching off near equipment and making ground connections as many as possible;

- $\quad$ waiting for congenial weather.

UST method is not so affected by electrical field. In UST capacitive currents flow direct to ground through power transformer's high voltage (HV) winding. In GST (Grounded Specimen Test) the similar currents flow through HV winding, through one of measuring bridge circuit and to ground. The other influence of electrical field can be the cause of $\tan \delta$ changes in measuring with GST method. It is the result of partial discharge between tested object's high voltage output and other under voltage system's equipment. It is the reason for higher $\tan \delta$ [6].

If $\tan \delta$ values are comparatively similar $\tan \delta$ values can be calculated (4) using measurements in two polarities which differ on $180^{\circ}$

$$
\tan \delta=\frac{\tan \delta^{\prime} R_{3}^{\prime}+\tan \delta^{\prime \prime} R_{3}^{\prime \prime}}{R_{3}^{\prime}+R_{3}^{\prime \prime}}=\frac{\tan \delta^{\prime} C_{X}^{\prime}+\tan \delta^{\prime \prime} C_{X}^{\prime \prime}}{C_{X}^{\prime}+C_{X}^{\prime \prime}},
$$

Electrical Machines and Apparatus / Elektriskās Mašīnas un Aparāti where:

$\tan \delta^{\prime}-$ object dielectric losses in first measurement, $\tan \delta^{\prime \prime}-$ object dielectric losses in second measurement, $R_{3}^{\prime}$ - the first measured resistance by measuring equipment, $R_{3}$-the second measured resistance by measuring equipment, $C_{x}^{\prime}$ - object capacitance in first measurement,

$C_{x}^{\prime \prime}$ - object capacitance in second measurement.

Near to the ideal conditions, when $\tan \delta$ in both polarities is low equation (5) can be used

$$
\tan \delta=0,5\left(\tan \delta^{\prime}+\tan \delta^{\prime \prime}\right) \text {. }
$$

\section{UNCONVENTIONAL MEASURING METHOD AND ITS EFFECTIVENESS}

It is very important to remember that the possibility of disturbance's elimination exists. This means that almost any part of tested object could be eliminated and has no further affect on measuring results. Using the guard methods acquired measuring results show the real technical condition of solid insulation in many cases.

In measuring of power transformers the guard test schema is often useful. In this case transformer tank is guarded. There is no influence of electrical field, since all proximal substation's equipment, which can affect on measuring results, is switched off by power transformer and another energized equipment is far enough from tested object (Tab.1. case D, E).

The many schemes and methods are known in diagnostic world, which are used for testing the equipment produced by IEC standards. Usually majority of energy companies decide not to maintain their equipment for the first 20 years (guaranty time from producer). However equipment produced by GOST standard has to be maintained and checked by diagnostic.

Therefore testing with complex methods using phase regulator and guard to obtain real result are not described in technical literature for various types of electrical. But it should be put into practice since application attempts produces suitable results as shown in the next chapter of this paper.

\section{CASE STUDY}

Dielectric losses tan $\delta$ is one of the main technical condition criteria; therefore close attention on its measurements has to be paid. It has rate-fixer values for each type of electrical equipment. Accordingly it is important to know by which method object has to be measured and how to get correct measuring results.

Before performing preventive or additional measurements the specialists must know:

- $\quad$ object's technical condition;

- previous measuring results;

- the reason of the last measurements;

- measuring conditions and applied method;

- rate-fixer values for specific electrical equipment.

General conclusion of practice shows that measuring results of simple methods are not correct due to electrical field's influence. For that reason the phase regulator must be applied. The guarding of surface minimizes the leakage current affect on measuring results. 
To avoid measuring mistakes, simple methods (GST and UST) should be used in ideal measuring conditions. For example, $110 \mathrm{kV}$ current transformer (see Tab.1. case C) which is produced in accordance with GOST standard in the end of $80 \mathrm{~s}$ has $3.5 \%$ rate-fixer value for dielectric losses. Measuring results obtained by traditional method often is out of range, at the same time two polarities method gives results which aren't out of range and with guard method the influence of electric field is minimized. Measuring results is real and correct. Therefore wrong decision making about technical condition is reduced.

Other previously described practical examples of tan $\delta$ measurements in substation under electrical field influence are summarized in Tab. 1.

It is important to remember that dielectric losses of insulating oil affect on dielectric losses of solid insulation. In that case measuring specificities do not have notable effect on $\tan \delta$ value.

TABLE I

RESULTS OF MEASUREMENTS

\begin{tabular}{|c|c|c|c|c|c|}
\hline \multirow[b]{2}{*}{ Equipment } & \multicolumn{3}{|c|}{ Measured quality values } & \multirow{2}{*}{$\begin{array}{l}\text { Insulation } \\
\text { level, } \\
(\mathrm{M} \Omega)\end{array}$} & \multirow[b]{2}{*}{ Notes } \\
\hline & Method & $\begin{array}{c}\text { Tan } \delta, \\
(\%)\end{array}$ & $\begin{array}{l}\mathrm{Cx}, \\
(\mathrm{pF})\end{array}$ & & \\
\hline \multirow{4}{*}{$\begin{array}{l}110 \mathrm{kV} \\
\text { current } \\
\text { transformer -A }\end{array}$} & I polarity & 0.65 & 94.0 & ---- & GST \\
\hline & II polarity & 1.60 & 105.6 & ---- & GST \\
\hline & Average & 1.13 & 99.8 & 189000 & GST \\
\hline & With guard & ---- & ---- & ---- & UST \\
\hline \multirow{4}{*}{$\begin{array}{l}110 \mathrm{kV} \\
\text { current } \\
\text { transformer -B }\end{array}$} & I polarity & 3.00 & 96.7 & ---- & GST \\
\hline & II polarity & 2.80 & 107.4 & ---- & GST \\
\hline & Average & 2.90 & 102.05 & 31000 & GST \\
\hline & With guard & 2.47 & 92.7 & ---- & UST \\
\hline \multirow{5}{*}{$\begin{array}{l}110 \mathrm{kV} \\
\text { current } \\
\text { transformer -C }\end{array}$} & $\begin{array}{l}\text { Without } \\
\text { phase } \\
\text { regulator }\end{array}$ & 3.89 & 104.2 & 7600 & GST \\
\hline & I polarity & 3.11 & 107.9 & ---- & GST \\
\hline & II polarity & 3.65 & 110.4 & ---- & GST \\
\hline & Average & 3.38 & 109.15 & ---- & GST \\
\hline & With guard & 3.05 & 108.8 & 21500 & UST \\
\hline \multirow{2}{*}{$\begin{array}{l}\text { Power } \\
\text { transformer's } \\
110 \mathrm{kV} \\
\text { bushing -D }\end{array}$} & $\begin{array}{l}\text { Without } \\
\text { phase } \\
\text { regulator }\end{array}$ & 0.38 & 168.64 & 254000 & UST \\
\hline & $\begin{array}{l}\text { Without } \\
\text { phase } \\
\text { regulator }\end{array}$ & 0.26 & 452.38 & 51500 & GST \\
\hline \multirow{3}{*}{$\begin{array}{l}110 \mathrm{kV} \text { power } \\
\text { transformer }-\mathrm{E}\end{array}$} & $\begin{array}{c}\text { Without } \\
\text { phase } \\
\text { regulator }\end{array}$ & 0.17 & 11802 & 39400 & $\begin{array}{l}\text { GST, } \\
\text { HV- } \\
\text { Ground }\end{array}$ \\
\hline & $\begin{array}{l}\text { Without } \\
\text { phase } \\
\text { regulator }\end{array}$ & 0.23 & 11241 & 45600 & $\begin{array}{r}\text { GST, } \\
\text { LV1- } \\
\text { Ground }\end{array}$ \\
\hline & $\begin{array}{l}\text { Without } \\
\text { phase } \\
\text { regulator }\end{array}$ & 0.22 & 10804 & 37200 & $\begin{array}{l}\text { GST, } \\
\text { LV2- } \\
\text { Ground }\end{array}$ \\
\hline
\end{tabular}

\section{CONCLUSIONS}

GST and UST methods are good in ideal conditions: in the high voltage testing laboratory and etc. To avoid measuring mistakes while testing electrical equipment in substation the specific measuring equipment and knowledge of substation's field influence on measuring results is required.
Electrical Machines and Apparatus / Elektriskās Mašīnas un Aparāti

The use of various methods gives accurate and believable results. Two polarities method is the best way how to minimize the influence of substation's electrical field. However if the efforts to prevent the effect of electrical field influence is poor and $\tan \delta$ value is still negative, it means that measuring should be stopped and another fault should be looked for.

Example described in Table 1 case $\mathrm{C}$ shows that the use of more complex measuring methods allows to avoid unreasonable costs relevant with equipment replacement and extend it remaining lifetime per some time period.

\section{REFERENCES}

[1] S. Ramo, J.R. Whinnery, and T. Van Duzer, Fields and Waves in Communication Electronics, 3rd ed. New York: John Wiley and Sons, 1994.

[2] www.capacitors.com,"DF,Q and ESR" [Online]. Available: http://www.cartage.org.lb/en/themes/sciences/physics/electromagnetism/ electrostatics/Capacitors/Applications/BasicConsiderations/BasicConsid erations.htm. [Accessed Feb.4, 2010].

[3] S. P. Mehta and W. R. Henning, "Transformer Testing, part 3.16" current ed. ANSI/IEEE C57.12.00-1993.

[4] G. Gavrilovs, "The analyses of $330 \mathrm{kV}$ un $110 \mathrm{kV}$ power transformer technical condition, basis on preventive test and insulating oil physicalchemical analyses results" M.S. thesis, Riga Technical University, Riga, Latvia, 2008.

[5] Fairchild Semiconductor Corporation, "Application Note 42047 Power Factor Correction (PFC) Basics," Fairchild Semiconductor [Online]. Available: http://www.fairchildsemi.com/an/AN/AN-42047.pdf. [Accessed: Jul. 12, 2010].

[6] Г.Н. Александров, В.Л. Иванов, Изоляция электрических аппаратов высокого напряжения. Ленинград: Энергоатомиздат, 1984.

[7] С.А. Бажанов, Техническое обслуживание $и$ ремонт вводов $и$ изоляторов высокого напряжения. Москва: Энергоатомиздат, 1984.

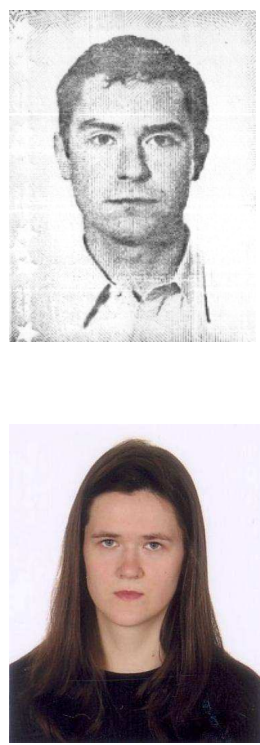

Gerards Gavrilovs

PhD student

Riga Technical University,

Power Engineering Institute

Adress: Kronvalda blv. 1, LV-1010, Riga

Phone: +371 26472039

Email: gerards.gavrilovs@ latvenergo.lv

Research interests: Prognosis and risk analyse of high-power transformers technical condition.

\section{Sandra Vītolina}

Dr.sc.ing., docent

Riga Technical University,

Power Engineering Institute

Adress: Kronvalda blv. 1, LV-1010, Riga

Phone: +371 67089418, fax 67089418

Email: sandra.vitolina@rtu.lv

Research interests: technical condition's assessment of high-power electrical machines 